\title{
Coronarography in Patients with Factor XI deficiency: A Literature Review
}

\author{
Mokhtar Abdallah ${ }^{1^{*}}$, Georges Khoueiry ${ }^{3}$ and Tarek Abdallah ${ }^{2}$ \\ ${ }^{1}$ Department of Medicine, Baton Rouge General Hospital, 8585 Picardy Ave, Baton Rouge, LA-70809, USA \\ ${ }^{2}$ Department of Pulmonary Medicine, North Oaks Health System, 15790 Medical Center Dr.Hammond, Louisiana-70403, USA \\ ${ }^{3}$ Department of Cardiology, North Oaks Health System, 15790 Medical Center Dr, Hammond, Louisiana-70403, USA \\ *Corresponding author: Mokhtar Abdallah, Department of Medicine, Baton Rouge General Hospital, 8585 Picardy Ave, Baton Rouge, LA-70809, USA, Tel: \\ 9179129768; E-mail: mk_abdullah@hotmail.com
}

Received date: Oct 16, 2015, Accepted date: Feb 27, 2016, Publication date: Feb 29, 2016

Copyright: ( 2016 Abdallah M, et al. This is an open-access article distributed under the terms of the Creative Commons Attribution License, which permits unrestricted use, distribution, and reproduction in any medium, provided the original author and source are credited.

\begin{abstract}
Hemophilia C or Factor XI deficiency is a hypocoagulable state leading to increased bleeding diathesis. Acute coronary syndrome can be manifested with chest pain and require a coronography to investigate the reason of the symptoms. This type of procedure requires the use of heparin and the possible need for oral antiplatelets especially if a stent was deployed. The use of anticoagulants or antiplatelets to prevent stent clotting becomes a challenge in patients with hypocoagulable state including patients with Hemophilia $\mathrm{C}$. We will summarize in our review the approach taken in similar cases described in literature.
\end{abstract}

Keywords: Hemophilia C; Factor XI deficiency; Coronorography

\section{Introduction}

Factor XI deficiency or Hemophilia C, an autosomal transmitted coagulopathy that is mostly seen in Ashkenazi Jews, was first described in 1953 by Rosenthal et al. as "hemophilia like disease"[1]. Clinical presentation is different and patients can be asymptomatic. In these cases the diagnosis is usually suspected based on a high activated partial thromboplastin time (aPTT) and confirmed by a low factor XI level. Plasma factor XI is mainly synthesized by the liver; it's an essential glycoprotein in the early phase of coagulation in vivo. During the contact phase, Factor XI plays a role in the generation of additional thrombin via a positive feedback mechanism [2]. The plasma level of FXI under $15 \mathrm{U} / \mathrm{Dl}$ or $15 \%$ of activity is considered as severe FXI deficiency and below the level of $70 \mathrm{U} / \mathrm{dL}$ or $70 \%$ activity is considered as mild deficiency [3]. Factor XI levels do not always correlate with the severity of bleeding even in homozygous patients. Bleeding is not usually spontaneous and is more common to occur in areas of high fibrinolysis such as dental extractions, tonsillectomy, urological surgery and nasal surgery [4]. In addition factor XI was isolated from washed platelets with a concentration that remained the same after successive washes, and a complete antigenic identity with plasma Factor XI [5-8]. The role of platelets factor XI has been uncertain so far, and although they contribute to less than $1 \%$ of the total activity of factor XI in blood, they might substitute for the deficient plasma factor XI [9-12]. This is ellucidated by the fact that patients with severe plasma factor XI deficiency and a normal homeostasis had a normal level of platelets factor XI, whereas patients with abnormal homeostasis had an abnormal platelets level component [8,11-13]. This might depict the need for anticoagulation in patients with myocardial infarction and during PCI, despite the fact that the PTT is increased in these patients. Moreover, factor XI deficiency was shown to be associated with a reduced incidence of ischemic stroke, but no effect on the incidence of myocardial infarction [5]. This relative protection against ischemic stroke is possibly secondary to the increased abundance of amyloid protein precursor protein, which promotes fibrinolytic activity, in the cerebral vasculature as opposed to the heart, in which it is probably absent [6,7].

\section{Discussion}

Reversal of factor XI deficiency with fresh frozen plasma transfusion (FFP) has been the conventional treatment when doing procedures. In cases of cardiac intervention this is followed by heparin infusion when needed to decrease the thrombotic risk associated with these procedures. However FFPs transfusion can lead to the development of antibodies to factor XI, an entity known as" factor XI inhibitors". The reversal of this condition is more complicated, because it necessitates the infusion of factor XI/pro-complex concentrate that might cause life-threatening thrombotic complications, including arterial thrombi in $10 \%$ of treated patients, particularly in older patients with preexisting coronary artery disease [14]. Immunotherapy or plasma exchange is another alternative, but its feasibility is limited in cases of acute coronary syndromes because of the acuity of the condition. There are some reports that recombinant FVIIa has successfully prevented bleeding during or after surgery in patients with FXI inhibitors [15]. To our knowledge, four cases have been described so far in patients with factor XI deficiency who needed to have a PCI. In Table1, we summarize the management of these cases, including:

1. indication for PCI,

2. the medical treatment received prior to PCI,

3. the history of bleeding in the past as reported in the articles,

4. baseline aPTT and factor XI level,

5. the site of access,

6. anticoagulation time (ACT) during the procedure,

7. the total dose of heparin including the dose administered after puncturing the site and the dose administered after intervention on the coronary arteries during catheterization,

8. the use or not of FFPs,

9. the type of intervention (i.e. stent, angioplasty),

10. the medical treatment after intervention, 
11. the closure device,

12. the findings on intravascular ultrasound (IVUS) imaging,

13. the outcomes regarding bleeding after intervention. Avi Shimony and Lee $\mathrm{SH}$, reported the traditional usage of FFPs transfusion prior to the procedure, followed by intravenous heparin administration and a close monitoring of the ACT during catheterization $[16,17]$.

Kaku B described a case of PCI in a patient with unknown history of factor XI deficiency, her diagnosis was suspected because of high ACT during the first PCI done for worsening effort angina [18]. Interestingly, a second PCI with a favorable outcome was done within the same admission without the use of FFPs nor heparin. The risk of thrombosis without the use of heparin was likely less in this case because no lipid pool was seen in the fibrous plaques during the intravascular ultrasound. It was shown that tissue factor (TF) is relatively abundant in the acellular lipid core, and it seems to predict the thrombogenicity of the plaque [19-21]. The lack of lipid pool in this patient's plaque has most likely played a major role in the favorable non-thrombotic outcome of this intervention without the use of heparin. The final patient described by S. Mungee had the most complicated history of factor XI deficiency among the four patients described in our review, with multiple episodes of severe bleeding and FFPs transfusion in the past complicated by acquired factor XI inhibitors [22]. Transfusion of FFPs prior to PCI in patients with factor XI inhibitors would not correct their aPTT or their coagulation deficiency. The uneventful non-thrombotic outcome of his PCI despite the lack of "heparinization" could be either explained by the presence of factor XI antibodies or the fact that the patient did not present with ACS. Tissue factor forms a high-affinity complex with coagulation factors VII and VIIa; TF-VIIa complex activates factors IX and X, which in turn leads to thrombin generation $[23,24]$. TF expression is markedly increased in plaques derived from patients with ACS as opposed to stable angina patients [25].

\begin{tabular}{|c|c|c|c|c|c|}
\hline Author & Avi Shimony & Lee SH & \multicolumn{2}{|l|}{ Kaku B* } & S. Mungee \\
\hline Age/Sex & $82 / \mathrm{M}$ & $52 / \mathrm{M}$ & \multicolumn{2}{|l|}{$84 / F$} & $72 / \mathrm{M}$ \\
\hline Indication for $\mathrm{PCl}$ & NSTEMI & Unstable angina & Worsening effort angina & $\begin{array}{l}\text { Symptomatic residual } \\
\text { RCA stenosis }\end{array}$ & Positive stress test \\
\hline Prior to $\mathrm{PCl}$ & Aspirin/Plavix & Aspirin/Plavix & Aspirin/Plavix & - & Aspirin \\
\hline Bleeding history & Profound bleeding & none & After dental procedures & - & $\begin{array}{l}\text { Severe/Acquired } \\
\text { inhibitor }\end{array}$ \\
\hline aPTT baseline & 77 & $>100$ & - & 148 & 78 \\
\hline Factor XI Level & 2.8 & 1.7 & - & $<3$ & $<1$ \\
\hline Approach & Transradial & Femoral & Femoral & Radial & Femoral \\
\hline ACT & 270 & 230 & $>1500$ & 249 & 420 \\
\hline Heparin & 9000 & 7500 & 8000 & None & None \\
\hline Use of FFP & Yes & Yes & No & No & No \\
\hline Intervention & DESx2 & DESx 1 & DESx1 & DESx2 & Balloon \\
\hline After $\mathrm{PCl}$ & Aspirin/Plavix & Aspirin/Plavix & Aspirin/Plavix & Aspirin/Plavix & Aspirin \\
\hline Closure device & - & Angioseal & - & - & Perclosure \\
\hline IVUS & - & Huge calcified plaques. & - & $\begin{array}{l}\text { Fibrous plaques without } \\
\text { lipid pool. }\end{array}$ & - \\
\hline Outcome & Uneventful & Uneventful & Uneventful & Uneventful & Uneventful \\
\hline
\end{tabular}

Table 1: FFPs transfusion prior to the procedure.

\section{Conclusion}

We try in our review to disclose the hesitancy in the era of anticoagulation when treating a patient with factor XI deficiency presenting with angina. It seems reasonable to differentiate between two groups of patients: acute coronary syndrome and stable angina. As we mentioned above, patients with stable angina can be managed offheparin because the risk of thrombotic events is less while manipulating their plaques during PCI. This distinction becomes particularly important in patients with history of severe bleeding diathesis or acquired factor XI inhibitors. Another helpful clue is the lipid content of the plaque seen on IVUS imaging. A poor-lipid plaque is less rich in tissue factor, an important modulator and predictor of plaque thrombogenicity. As in patients with stable angina, PCI in cases of poor-lipid plaques might be done without heparin.

In circumstances where long treatment with dual anti-platelets is to be avoided, balloon-angioplasty with no anticoagulation (i.e. Heparin, $\mathrm{LMWH}$ ) other than aspirin seems to be the practical choice. In cases where stenting cannot be avoided, a heparin or phosphorylcholine coated stent should be considered. The thrombin-antithrombin III complex (TAT) level can reflect the burden of thrombogenicity after PCI [26]. We are not sure if following the TAT level over weeks can help in shortening a required duration of clopidogrel treatment in 
addition to aspirin after drug-eluting, long stent placement, or imperfect result.

Based on the results of the cases descried in our review, the traditional use of FFP followed by heparin during PCI appears to be a safe method in patients with no or minimal history of bleeding. Intervention type (i.e. stent) might need to be judged independently of the history of factor XI deficiency in these cases.

\section{References}

1. Rosenthal RL, Dreskin OH, Rosenthal N (1953) New hemophilia-like disease caused by deficiency of a third plasma thromboplastin factor. Proc Soc Exp Biol Med 82: 171-174.

2. Bolton-Maggs PH1 (2009) Factor XI deficiency--resolving the enigma? Hematology Am Soc Hematol Educ Program.

3. Salomon O, Seligsohn U (2004) New observations on factor XI deficiency. Haemophilia 10 Suppl 4: 184-187.

4. Asakai R, Chung DW, Davie EW, Seligsohn U (1991) Factor XI deficiency in Ashkenazi Jews in Israel. N Engl J Med 325: 153-158.

5. Salomon O, Steinberg DM, Koren-Morag N, Tanne D, Seligsohn U (2008) Reduced incidence of ischemic stroke in patients with severe factor XI deficiency. Blood 111: 4113-4117.

6. Wagner SL, Van Nostrand WE, Lau AL, Farrow JS, Suzuki M, et al. (1993) Co-distribution of protease nexin-1 and protease nexin-2 in brains of non-human primates. Brain Res 626: 90-98.

7. Davis J, Wagner MR, Zhang W, Xu F, Van Nostrand WE (2003) Amyloid beta-protein stimulates the expression of urokinase-type plasminogen activator (uPA) and its receptor (uPAR) in human cerebrovascular smooth muscle cells. J Biol Chem 278: 19054-19061.

8. Tuszynski GP, Bevacqua SJ, Schmaier AH, Colman RW, Walsh PN (1982) Factor XI antigen and activity in human platelets. Blood 59: 1148-1156.

9. Walsh PN (1972) Albumin density gradient separation and washing of platelets and the study of platelet coagulant activities. Br J Haematol 22: 205-217.

10. Schiffman S, Rimon A, Rapaport SI (1977) Factor XI and platelets: Evidence that platelets contain only minimal factor XI activity and antigen. Br J Haematol 35: 429-436.

11. Lipscomb MS, Walsh PN (1979) Human platelets and factor XI. Localization in platelet membranes of factor XI-like activity and its functional distinction from plasma factor XI. J Clin Invest 63: 1006-1014.

12. Walsh PN (1974) Platelet coagulant activities and hemostasis: a hypothesis. Blood 43: 597-605.
13. Ragni MV, Sinha D, Seaman F, Lewis JH, Spero JA, et al. (1985) Comparison of bleeding tendency, factor XI coagulant activity, and factor $\mathrm{XI}$ antigen in 25 factor XI-deficient kindreds. Blood 65: 719-724.

14. Gitel SN, Varon D, Schulman S, Martinowitz U (1991) Clinical experiences of a FXI concentrate: possible side effects. Thromb Hemostas 65: 1157.

15. Lawler P, White B, Pye S, Hermans C, Riddell A, et al. (2002) Successful use of recombinant factor VIIa in a patient with inhibitor secondary to severe factor XI deficiency. Haemophilia 8: 145-148.

16. Shimony A, Levi E, Zahger D (2009) Percutaneous coronary intervention in a patient with factor XI deficiency. J Invasive Cardiol 21: E178-179.

17. Lee SH, Jeong MH, Sohn SIL, Lim SY, Hong SN, et al. (2005) Successful Management of a Patient with Factor XI Deficiency and Unstable Angina by Percutaneous Coronary Intervention. Korean Circulation J 35: 860-886.

18. Kaku B, Shimojima M, Yoshida T, Katsuda S, Taguchi T, et al. (2012) Coronary artery stenting in a patient with factor XI deficiency. Cardiovasc Interv Ther 27: 99-104.

19. Toschi V, Gallo R, Lettino M, Fallon JT, Gertz SD, et al. (1997) Tissue factor modulates the thrombogenicity of human atherosclerotic plaques. Circulation 95: 594-599.

20. Marmur JD, Thiruvikraman SV, Fyfe BS, Guha A, Sharma SK, et al. (1996) Identification of active tissue factor in human coronary atheroma. Circulation 94: 1226-1232.

21. Badimon JJ, Lettino M, Toschi V, Fuster V, Berrozpe M, et al. (1999) Local inhibition of tissue factor reduces the thrombogenicity of disrupted human atherosclerotic plaques: effects of tissue factor pathway inhibitor on plaque thrombogenicity under flow conditions. Circulation 99: 1780-1787.

22. Mungee S, Lapin R, Cavusoglu E, Clark LT, Marmur JD (2007) Percutaneous coronary intervention in a patient with congenital factor XI deficiency and acquired inhibitor. Cardiology 107: 69-72.

23. Rapaport SI, Rao LV (1992) Initiation and regulation of tissue factordependent blood coagulation. Arterioscler Thromb 12: 1111-1121.

24. Nemerson Y (1988) Tissue factor and hemostasis. Blood 71: 1-8.

25. el Saegh MM, Aly MA, el Sayegh T, Mostafa EA, Zaghloul T, et al. (1993) Transseptal approach for mitral valve surgery. A safe alternative when the need calls. Tex Heart Inst J 20: 23-27.

26. Namiki A, Toma H, Nakamura M, Matsuda K, Hara H, et al. (2004) Hemostatic and fibrinolytic activation is less following cutting balloon angioplasty of the coronary arteries. Jpn Heart J 45: 409-417. 